\title{
Vulnerabilities of the Romanian Air Force pilot training system manifested in the flight training process
}

\author{
Eduard Ionut Mihai ${ }^{1, *}$, and Ioan Dănut Balos $^{2}$ \\ 1"Henri Coanda" Air Force Academy, Department of Aviation, 160 M. Viteazul, Brasov, Romania \\ ${ }^{2}$ Transilvania University of Brasov, Department of EIM, 5 M. Viteazul, Brasov, Romania
}

\begin{abstract}
The vulnerability of a flight instruction system is understood as a state of affairs, processes or phenomena in the organization's internal life that diminishes its ability to react to existing or potential changes. Starting from the results of previous research conducted by the authors, the article aims to highlight the need for new ways to train Air Force pilots and suggests possible solutions. The purpose of this study is thus to identify the areas of vulnerability proper to the organization providing the training by synthesizing survey results based on the subjects' professional experience. Accordingly, we deemed necessary and at the same time pertinent to consider the opinions of the staff involved in the practical training process. For this reason, the evaluation carried out between June and July 2018 involved the Aviation Training Group at "Aurel Vlaicu" Air Force Base.
\end{abstract}

\section{Introduction}

The uniqueness of fighter pilot training will impact on most of the important characteristics of the instruction system which, in their own turn, will determine the level of performance of the educational process. Understanding the concept of training as well as raising awareness on current failures must be a perpetual concern of all the actors involved in the training of younger generation pilots in order to create an efficient, stable and safe aeronautical environment.

The overall objective our study focuses on is that of identifying the level of vulnerability specific to the flight instruction system dedicated to the training of flying personnel in the Romanian military aeronautical system.

In accordance with this general objective, we have set the following specific objectives:

- to determine the extent to which the current training system meets the training requirements specific to Air Force missions;

- to identify the shortcomings of the training process and the degree of awareness of the staff involved;

- to inquire about the opinion of the subjects on management involvement, staff training, employee motivation and the situation of technical endowment, as far as the quality of the training provided to Air Force pilots is concerned;

\footnotetext{
* Corresponding author: mishued2004@gmail.com
} 
- to set the groundwork for future research on the possibilities of streamlining the processes related to pilot practical training.

With these objectives in mind, we were able to define the hypotheses articulating our questionnaire-based research, namely:

- there is a degree of vulnerability in the aeronautical training system which has to be determined;

- the National Defense System's lack of sufficient material and financial resources spawns the emergence of certain high vulnerability spots in the optimal training of future Air Force pilots;

- by reducing the number of training hours, the current system does not allow for the acquisition of sufficient theoretical and practical knowledge, which has negative effects on the results of the training process;

- irrespective of the external difficulties affecting the instruction providers' work, they take the training of future Air Force pilots seriously.

\section{Data management techniques}

To carry out this research, we opted for the survey method, having a questionnaire designed in cooperation with the Air Force Training School's Psychologist, Mrs. Clara Neacsu, as an instrument.

Our option was motivated by our interest in providing an up-to-date overview of the vulnerabilities that, according to the opinions and attitudes expressed by survey participants, currently characterize the flight instruction system designed for the training of Air Force pilots. Likewise, another reason having influenced our choice was our concern for time efficiency: reducing the time resources respondents had to allocate to this questionnaire to a minimum efficiently avoided refusals to participate.

Focusing on the said vulnerabilities, the questionnaire included 22 closed items rated according to the Likert agreement scale [1]. Numerical values were assaigned to each of the five Lickert scales as follows:

- to a very limited extent, not at all - 1 ;

- to a small extent - 2 ;

- to a certain extent -3 ;

- to a large extent -4 ;

- to a great extent, always -5 .

Thus, an average score that comes close to " $1 "$ indicates a maximum level of system efficiency (lack of vulnerabilities), while an average score nearing "5" indicates a maximum inefficiency area, with vulnerabilities and critical items. For the interpretation of results, we grouped the 22 items into four categories refering to the characteristics of the Air Force pilot training process. The conceptual variables we will focus on are: organizational policies, theoretical and practical training, staff motivation, technical factors, and resource allocation; these variables were selected because they were thought to affect the performance levels of the training system. The individual variables included in the analysis capture the age and rank of the subjects under consideration.

The questionnaires were individually administered, and the fact that they were unsigned was meant to encourage the participants' honest and pertinent answers. The group of subjects described in Table 1 comprises flight instructors, pilots and non-flying personnel, whose age segment is between 24 and 52 years. The margin of error as far as sampling is concerned was of $\pm 3 \%$ at a probability level of $95 \%$.

As far as categories are concerned, we must specify that the pilots' refers to those who received a posting of instructor but do not yet hold this qualification, and that of the non- 
flying personnel includes the traffic controllers and squadron senior staff officers directly involved in the training process.

Table 1. The survey group according to three main professional categories

\begin{tabular}{|c|c|c|c|c|c|c|}
\hline \multirow{2}{*}{$\begin{array}{l}\text { Age Category } \\
\text { (years) }\end{array}$} & \multicolumn{2}{|c|}{ Pilots } & \multicolumn{2}{c|}{ Flight instructors } & Non-flying personnel \\
\cline { 2 - 7 } & Women & Men & Women & Men & Women & Men \\
\hline $\mathbf{2 4 - 2 9}$ & $\mathbf{2}$ & $\mathbf{4}$ & $\mathbf{1}$ & $\mathbf{1}$ & $\mathbf{1}$ & $\mathbf{2}$ \\
\hline $\mathbf{3 0 - 3 4}$ & - & $\mathbf{2}$ & - & $\mathbf{3}$ & $\mathbf{1}$ & $\mathbf{3}$ \\
\hline $\mathbf{3 5 - 3 9}$ & - & $\mathbf{1}$ & - & $\mathbf{5}$ & - & $\mathbf{3}$ \\
\hline $\mathbf{4 0 - 4 4}$ & - & - & - & $\mathbf{3}$ & - & $\mathbf{5}$ \\
\hline Over 45 & - & - & - & $\mathbf{1 1}$ & $\mathbf{1}$ & $\mathbf{4}$ \\
\hline
\end{tabular}

\section{Data processing and interpretation}

In the context of the present study, data processing refers to calculating the arithmetic mean of the answers for each item, then calculating the average value that represents the vulnerability level of each of the four dimensions. In what follows, we will discuss the survey results.

The chart in figure one shows the level of vulnerability of the instruction system in its four dimensions. The answers, calculated on a 5-stepped Lickert scale, range from 1 - "to a very limited extent" to 5 - "to a great extent", represent the fact that the participants' opinions go from "total disagreement" to "complete agreement", where 3 is the average value - "neither strong disagreement, nor strong agreement".

The maximum value of 4.05 indicates that almost all participants consider resource allocation and technical equipment to be deficient, which designates these two as the most vulnerable areas. The theoretical and practical staff training system ranks second, at a similar value of 3.68 .

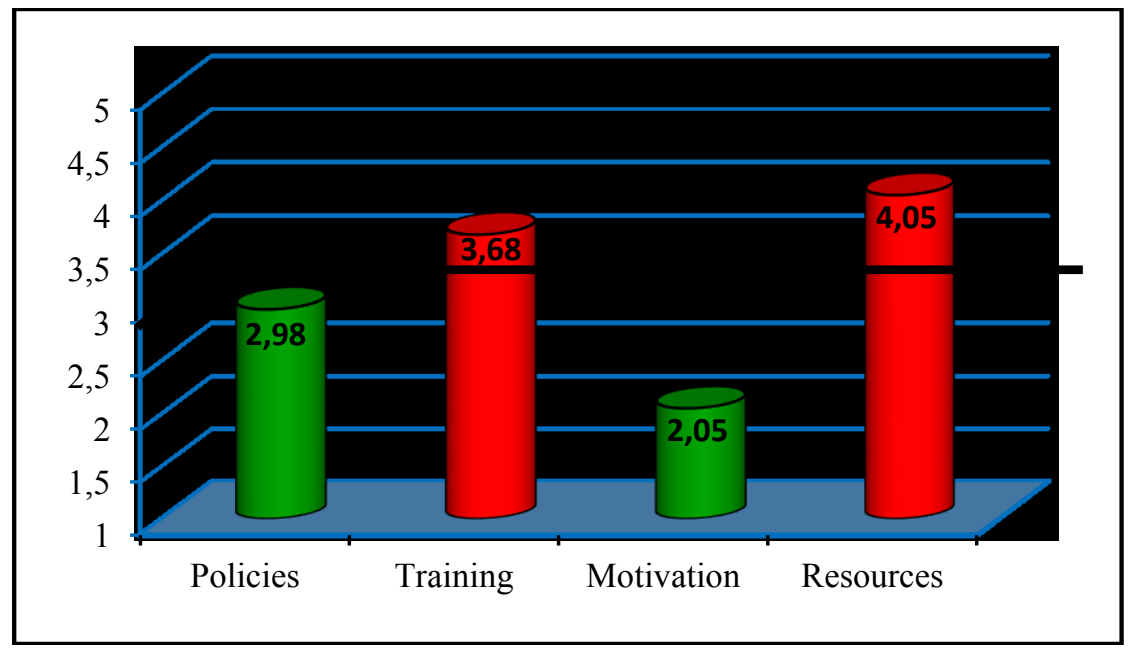

Fig. 1. Vulnerability level values corresponding to the four research dimensions

Organizational policies and the organization's attitude in relation to the training process, which remains an organizational responsibility, reach an average of 2.98 , which places this dimension on a neutral vulnerability level, showing that the organization does not have a negative impact on training, but is not actively involved in creating an optimal environment, either. 
Staff motivation capacity also scored below the average level 3, amounting to 2.05. According to the participants, this dimension attains positive levels of vulnerability.

The thick black horizontal line indicates the average value 3 . The scores are considered to be positive below the line and negative above the line.

The overall average value of 3.19 , representing organizational vulnerability, exceeds the neutral value, a negative tendency which indicates that the subjects believe they are operating in an environment where there are potential threats and risks. All four dimensions require major improvements, with no respondent assigning positive value to the entire measurement scale.

The item having resulted in the highest vulnerability score (4.63) is the following: "The resources allocated to the training of Air Force pilots are insufficient". According to the assumption, the country's current economic situation does not allow for the allocation of considerable budgetary funds, neither for the maintenance and upgrading of the current technical equipment, nor for the acquisition of new technologies.

The flying personnel operates in a high-risk environment where pilot maintenance training is carried out on aircraft whose resource has been prolonged several times or, worse, whose resource is in depletion. Much in the same way, the item according to which "The lack of a long-term, predictable and coherent concept has a negative impact on the Air Force training process" registered a high level of vulnerability (4.51).

Table 2. Vulnerability level values corresponding to the four research dimensions

\begin{tabular}{|c|c|c|c|}
\hline DIMENSIONS & $\begin{array}{c}\text { AVERAGE VALUE OF THE } \\
\text { VULNERABILITY LEVEL }\end{array}$ & $\begin{array}{c}\text { MAXIMAL } \\
\text { VALUE }\end{array}$ & $\begin{array}{c}\text { MINIMAL } \\
\text { VALUE }\end{array}$ \\
\hline Organizational policies & $\mathbf{2 . 9 8}$ & $\mathbf{4 . 5 1}$ & $\mathbf{1 . 8 6}$ \\
\hline $\begin{array}{c}\text { Theoretical and practical } \\
\text { training }\end{array}$ & $\mathbf{3 . 6 8}$ & $\mathbf{4 . 4 9}$ & $\mathbf{2 . 7 4}$ \\
\hline Staff motivation & 2.05 & $\mathbf{2 . 9 6}$ & 1.26 \\
\hline $\begin{array}{c}\text { Resource allocation and } \\
\text { tachnical factors }\end{array}$ & 4.05 & 4.53 & $\mathbf{2 . 8 2}$ \\
\hline
\end{tabular}

An increased awareness about the existing organizational deficiencies and a deeper understanding of the importance the training system holds is demonstrated by the fact that almost all respondents have positive opinions on the need to introduce a specific concept that of an Air Force Pilot Training System - at the level of the entire service branch.

The item that received the highest positive evaluation as compared to the maximum value stated that "The training system and the tasks imposed by it are insufficient and inadequately known" and was closely followed by an item according to which "There are various issues that, although solvable and easily identified, still affect the flight instruction system". The respective scores of 1.26 and 1.30 indicate that the participants disagreed with the given statements.

Further information on the strengths and vulnerabilities of the training system can be observed by analyzing the average values per item in the context of each dimension taken separately.

\section{Discrete results analysis according to each research dimension}

As far as the organizational policies related to the training process are concerned, the respondents were moderate in their evaluation of the organization's attitude regarding the training of military pilots. Most items, except for the first two, recorded positive values (see Table 3). As mentioned above, the main problem, rated at 4.51, is the lack of a long-term view of the Air Force pilot training process. According to the participants, an equally 
serious issue to be considered concerns the absence of a concept to specifically describe the Air Force Pilot Training System (4.02). The item attaining the highest positive value (1.86) refers to the representation of the institutions providing the training at the level of higher structures. All these assessments have brought us to the general conclusion that this area does not negatively affect the training process, but should make a greater contribution to the training of flying personnel members [2].

Table 3. Mean values of participants' responses concerning organizational policies

\begin{tabular}{|c|l|c|}
\hline $\begin{array}{c}\text { Item } \\
\text { No. }\end{array}$ & \multicolumn{1}{|c|}{ ITEMS } & VALUES \\
\hline 1 & $\begin{array}{l}\text { The lack of a long-term, predictable and coherent view of the Air Force } \\
\text { pilot training process is evident. }\end{array}$ & 4.51 \\
\hline 2 & $\begin{array}{l}\text { The idea of introducing the concept of an "Air Force Pilot Training } \\
\text { System" is inappropriate. }\end{array}$ & 4.02 \\
\hline 3 & $\begin{array}{l}\text { The organization's management is not interested in meeting present-day } \\
\text { specific training requirements. }\end{array}$ & 1.98 \\
\hline 4 & $\begin{array}{l}\text { The institutions providing the training are not well represented at the level } \\
\text { of higher structures (The Ministry of National Defence, The General } \\
\text { Staff, The Air Force Staff etc.). }\end{array}$ & $\mathbf{1 . 8 6}$ \\
\hline 5 & $\begin{array}{l}\text { There are conflicts among decision-makers in your organization about } \\
\text { how to train students and graduates. }\end{array}$ & 2.69 \\
\hline 6 & $\begin{array}{l}\text { There are incorrect priorities regarding the training of future air force } \\
\text { pilots at the level of the organization's management. }\end{array}$ & 2.82 \\
\hline & \multicolumn{1}{|c|}{ MEAN VALUE } & $\mathbf{2 . 9 8}$ \\
\hline
\end{tabular}

According to Table 4, the average value of the calculated answer for the theoretical and practical staff training vulnerability reaches 3.68 and is higher than the general mean level. The subjects criticize the current educational system, which does not ensure the accumulation of an optimal level of theoretical and practical knowledge necessary for the smooth running of the training process. Moreover, the small number of flight hours included in the curriculum affects the practical side of the training (3.91).

Table 4. Mean values of participants' responses concerning the theoretical and practical instruction process

\begin{tabular}{|c|c|c|}
\hline $\begin{array}{l}\text { Item } \\
\text { No. }\end{array}$ & ITEMS & VALUES \\
\hline 1 & $\begin{array}{l}\text { The current Air Force pilot training system is unable to develop the skills } \\
\text { and capabilities future graduates need in order to operate multirole } \\
\text { aircraft, especially F-16s. }\end{array}$ & 2.78 \\
\hline 2 & $\begin{array}{l}\text { Current higher education does not allow the acquisition of sufficient } \\
\text { theoretical knowledge for the requirements of modern aviation. }\end{array}$ & 3.82 \\
\hline 3 & $\begin{array}{l}\text { Flight instruction does not allow the accumulation of knowledge and } \\
\text { practical skills essential to an Air Force pilot's career. }\end{array}$ & 3.91 \\
\hline 4 & The training program did not produce qualified and properly trained staff. & 2.74 \\
\hline 5 & $\begin{array}{l}\text { Training student pilots in non-MoD structures (Romanian Aviation } \\
\text { Academy - SSAvC) has a negative impact on the training process. }\end{array}$ & 4.49 \\
\hline 6 & $\begin{array}{l}\text { The documentation and procedures specific to flight instruction activities } \\
\text { are sketchy. }\end{array}$ & 4.34 \\
\hline 0 & MEAN VALUE & 3.68 \\
\hline
\end{tabular}

It is true that this category is strongly influenced by the fifth item that holds the highest negative score (4.49). This result is also emotionally biased, as respondents perceive the emergence of the School of Civil Aviation as a competitive structure as far as practical flight instruction is concerned. 
The most highly appreciated item in this category is the one concerning result of the training program. Subjects have assigned positive value to this aspect (2.74), deeming the vulnerability level acceptable.

One of the key components of the organization is its motivational dimension [3-5]. In this case, the values associated to it are positive and this is the area in which the best scores were obtained: according to Table 5, all the answers were under the mean, neutral value. The average value for this sector (2.05) brings an optimistic outlook in the overall assessment of the system's vulnerabilities, respondents acknowledging the decisive role of the motivational factor in the practical training activity.

Table 5. Mean values of participants' responses concerning the motivational dimension.

\begin{tabular}{|c|l|c|}
\hline $\begin{array}{c}\text { Item } \\
\text { No. }\end{array}$ & \multicolumn{1}{|c|}{ ITEMS } & VALUES \\
\hline 1 & $\begin{array}{l}\text { The training system and the tasks imposed by it are insufficient and } \\
\text { inadequately known. }\end{array}$ & $\mathbf{1 . 2 6}$ \\
\hline 2 & $\begin{array}{l}\text { There are motivational deficiencies among staff involved in the training } \\
\text { process. }\end{array}$ & $\mathbf{2 . 9 6}$ \\
\hline 3 & $\begin{array}{l}\text { Excessive time pressure and unbalanced workloads affects students' } \\
\text { motivation during practical training. }\end{array}$ & 2.47 \\
\hline 4 & $\begin{array}{l}\text { How about staff motivation when it comes to the personnel involved in } \\
\text { flight activities? }\end{array}$ & 2.14 \\
\hline 5 & $\begin{array}{l}\text { There are various issues which are not remedied, in spite of the fact that } \\
\text { they are solvable, easily identified and may affect the flight instruction } \\
\text { system. }\end{array}$ & 1.42 \\
\hline \multicolumn{2}{|c|}{ MEAN VALUE } & $\mathbf{2 . 0 5}$ \\
\hline
\end{tabular}

The fact that the participants' attitude concerning topics related to task-assignment in the context of the training system generated the lowest score in the entire questionnaire (1.26) must be also highlighted. There is only one item that marks a value closer to neutral, 2.96, the one referring to motivational deficiencies among staff members. These are determined by the pilots payment regime that places too much emphasis on variable incomes, derived from the number of flight hours or the complexity of the missions performed.

Table 6 - Mean values of participants' responses concerning resource allocation and endowment

\begin{tabular}{|c|l|c|}
\hline $\begin{array}{c}\text { Item } \\
\text { No. }\end{array}$ & \multicolumn{1}{|c|}{ ITEMS } & VALUES \\
\hline 1 & $\begin{array}{l}\text { The resources allocated to the training of Air Force pilots are } \\
\text { insufficient. }\end{array}$ & 4.53 \\
\hline 2 & $\begin{array}{l}\text { The current materiel is inadequate to the requirements of Air Force pilot } \\
\text { training. }\end{array}$ & 4.21 \\
\hline 3 & $\begin{array}{l}\text { The trainer aircraft in the aviation school are unsuitable for the training } \\
\text { process. }\end{array}$ & 4.41 \\
\hline 4 & The modernization of the current trainer aircraft fleet would be useful. & $\mathbf{2 . 8 2}$ \\
\hline 5 & $\begin{array}{l}\text { The replacement of the current trainer fleet with new aircraft is } \\
\text { unnecessary. }\end{array}$ & 4.28 \\
\hline \multicolumn{2}{|l|}{ MEAN VALUE } & $\mathbf{4 . 0 5}$ \\
\hline
\end{tabular}

As for the fourth dimension, concerning the resources allocated to the training system, most items recorded high vulnerability values, as shown in Table 6 . We have already mentioned that the main problem, reaching a score of 4.53 , is the insufficient resources allocated to the training system. The same criticism extends, in the respondents' perception, to the availability of the entire material and technological endowment and to the aircraft 
used by the military aviation school. These issues lead to a decrease in the quality of human resources and a lack of consistent support for the improvement of the training process. The only item having a positive value in this dimension (2.82) is the modernization of the aircraft currently in use, and the skepticism related to the idea of replacing them can be explained by the subjects' knowledge of the inner workings of the system.

As far as a comparative analysis of the results by groups is concerned, the general conclusion is that there were no significant differences between the opinions of flight instructors, other pilots and the non-flying personnel involved in flight activities regarding the general level of vulnerability of the training system. These values are shown in figure 2 : the difference between them is negligible, demonstrating the consistence of perception regarding the system's vulnerabilities.

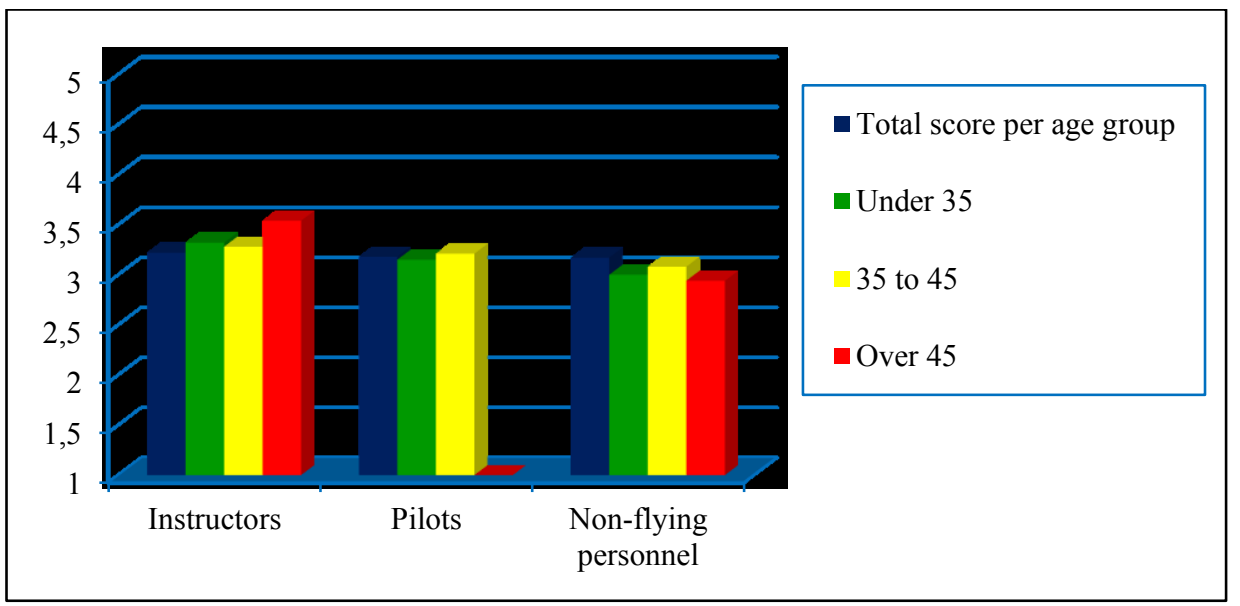

Fig. 2. The opinions of staff on the system's vulnerability indicator by age groups

Based on the same graph, we can notice that there are small differences between age categories, where the most critical group is that of experienced flight instructors. This fact is also determined by the exclusive presence of assessors and examiners in this age group. Note that there were no pilots belonging to the third age group (over 45) among the respondents.

There were no issues with data processing. The items didn't generate any comprehension difficulties and were considered relevant, with the answers being generally distributed from 1 to 5, indicating the various views on the vulnerabilities of the the Air Force pilot training system expressed by the participants.

\section{Conclusions}

As far as the analysis is concerned, the results confirm the initial assumptions and as expected, the vulnerability level of the system is above average, because of the critical items identified for each of the four dimensions considered in the study. The problematic aspects are closely related and mutually affect one another, problems such as the lack of material resources and the poor management of pilot training policies significantly affecting the general level of vulnerability [6].

The four organizational dimensions analyzed cover broad organizational and individual scopes. Subjects' opinions signal that our aeronautical military organizations are visibly vulnerable in terms of their structuring, policies, management, motivation levels and the training activities they provide, and less vulnerable at individual level. The risks generated by the organization outweigh individually assumed risks, this phenomenon indicating there 
are serious deviations from safety rules. In fact, a state of normality would imply an organization with a strong and well-developed organizational culture able to guide, motivate and support the staff in promoting safe, risk-free activities.

We believe that our study has reached its goal, that of mapping the distances between the "perfection" we should aim at and the real, restrictive economic conditions under which the Romanian military aviation school must function [7-8]. Addressing this issue is a step towards further analyses concerning the effectiveness of the education system's involvement in order to try and eliminate certain aspects we deem improper to Air Force educational processes.

The current attempt to determine the level of vulnerability in the Romanian flight instruction system, by means of the questionnaire we applied within the military institution responsible, showed us how the trainers involved perceive its specific problems.

Thus, the fact that the people and structures involved are willing to contribute by raising awareness [9] about the shortcomings hereby identified strengthens our belief that through its human capital, the training system can respond positively to the changes and challenges imposed by the emergence of new technologies and meet the specific requirements which characterise the education and training of future Air Force officers.

\section{References}

1. A. Joshi, S. Kale, S. Chandel, D. K. Pal, Br. J. Appl. Sci. Technol, Likert Scale: Explored and Explained, 7(4) (2015)

2. O. Ciuica, E.Mihai, Rev. Air F. Acad, The role of the first instructor in cultivating the aviation safety concept, 2(29) 43-46 (2015)

3. E. Mihai, O. Mosoiu, Rev. Air F. Acad, Analysis of the Romanian Air Force squadron organizational culture, 2(26) 29-33 (2014)

4. V. Grad, I. Stoian, E.C. Kovacs, V. Dumitru, Operational military research (Bucharest: Sylvi Publisher, 2000)

5. M. Popa, Aeronautical Psychology (Bucharest, 2005)

6. D. Maurino, TEM CASS, Flight safety and Human Factors Programme - ICAO, (2005)

7. J.S. Bruner, Towards theory of instruction, (EDP Publishing House, 1970)

8. D. Belu, Managementul organizației militare. Curs, (Brasov, 2010)

9. M. Vlăsceanu, Organizații și comportament organizațional, (Iași, 2003) 